\title{
Delivery Dependence of Early Proximal Bicarbonate Reabsorption in the Rat in Respiratory Acidosis and Alkalosis
}

\author{
Robert N. Santella, David A. Maddox, and F. John Gennari \\ University of Vermont, College of Medicine, Burlington, Vermont 05405
}

\begin{abstract}
In the intact rat kidney, bicarbonate reabsorption in the early proximal tubule (EP) is strongly dependent on delivery. Independent of delivery, metabolic acidosis stimulates EP bicarbonate reabsorption. In this study, we investigated whether systemic pH changes induced by acute or chronic respiratory acidbase disorders also affect $\mathrm{EP}_{\mathrm{HCO}}^{-}$reabsorption, independent of delivery ( $\mathrm{FL}_{\mathrm{HCO}_{3}}$, filtered load of bicarbonate). Hypercapnia was induced in rats acutely (1-3 h) and chronically (4-5 d) by increasing inspired $\mathrm{PCO}_{2}$. Hypocapnia was induced acutely (1$3 \mathrm{~h})$ by mechanical hyperventilation, and chronically (4-5 d) using hypoxemia to stimulate ventilation. When compared with normocapneic rats with similar $\mathrm{FL}_{\mathrm{HCO}_{3}}$, no stimulation of EP or overall proximal $\mathrm{HCO}_{3}$ reabsorption was found with either acute hypercapnia $\left(\mathrm{Pa}_{\mathrm{co}_{2}}=74 \mathrm{mmHg}, \mathrm{pH}=7.23\right)$ or chronic hypercapnia $\left(\mathrm{Pa}_{\mathrm{Co}_{2}}=84 \mathrm{mmHg}, \mathrm{pH}=7.31\right)$. Acute hypocapnia $\left(\mathrm{Pa}_{\mathrm{CO}_{2}}=29 \mathrm{mmHg}, \mathrm{pH}=7.56\right)$ did not suppress $\mathrm{EP}$ or overall $\mathrm{HCO}_{3}$ reabsorption. Chronic hypocapnia $\left(\mathrm{Pa}_{\mathrm{co}}=26 \mathrm{mmHg}\right.$, $\mathrm{pH}=7.54$ ) reduced proximal $\mathrm{HCO}_{3}$ reabsorption, but this effect was reversed when $\mathrm{FL}_{\mathrm{HCO}_{3}}$ was increased to levels comparable to euvolemic normocapneic rats. Thus, when delivery is accounted for, we could find no additional stimulation of proximal bicarbonate reabsorption in respiratory acidosis and, except at low delivery rates, no reduction in bicarbonate reabsorption in respiratory alkalosis. (J. Clin. Invest. 1991. 87:631638.) Key words: hypercapnia - hypocapnia - pH • acid-base disorders
\end{abstract}

\section{Introduction}

The first $1-2 \mathrm{~mm}$ of the proximal tubule of the rat nephron is a high capacity site for bicarbonate reabsorption, normally recapturing some $50-60 \%$ of filtered bicarbonate (1-8). Bicarbonate reabsorption at this site in the nephron, moreover, varies in direct relation to the filtered or perfused load over a wide range of loads $(2,4-10)$. In addition to delivery, a variety of studies of bicarbonate transport in isolated tubule segments in vivo or in vitro have shown that acidosis stimulates and alkalosis inhibits proximal bicarbonate reabsorption (11-16). The extent to which systemic $\mathrm{pH}$ influences proximal bicarbonate reabsorption in the intact kidney, however, is unclear. In a previous free-flow micropuncture study, we showed that

Address reprint requests to Dr. F. John Gennari, University of Vermont, College of Medicine, Given Building, Burlington, VT 054050068 . 1990.

Received for publication 11 April 1990 and in revised form 25 June

J. Clin. Invest.

(c) The American Society for Clinical Investigation, Inc.

0021-9738/91/02/0631/08 $\$ 2.00$

Volume 87, February 1991, 631-638 chronic metabolic acidosis stimulated bicarbonate reabsorption in the early proximal tubule, independent of delivery (17). Chronic metabolic alkalosis, however, does not dampen bicarbonate reabsorption in the early proximal tubule, despite an alkaline $\mathrm{pH}(2,5)$.

In studies of isolated perfused tubules in the rabbit, changes in bath $\mathrm{Pa}_{\mathrm{CO}_{2}}$ have been demonstrated to influence bicarbonate reabsorption profoundly in the early proximal tubule (11). However, no assessment of early proximal bicarbonate reabsorption under free-flow conditions has been carried out in respiratory acid-base disorders. Studies of end proximal reabsorption in the rat have not shown such profound effects after acute changes in $\mathrm{Pa}_{\mathrm{CO}_{2}}$. In acute respiratory alkalosis, proximal bicarbonate reabsorption is reduced slightly $(18,19)$, but acute respiratory acidosis does not appear to stimulate reabsorption $(19,20)$.

These studies were undertaken to assess the role of $\mathrm{pH}$ in the regulation of early and overall proximal bicarbonate reabsorption in the intact rat kidney during respiratory acid-base disorders. To take into account the influence of delivery, we compared bicarbonate reabsorption in rats with respiratory acidosis or alkalosis to that in rats with similar filtered loads of bicarbonate but with normal acid-base parameters. When delivery was accounted for, we could detect no additional stimulation of bicarbonate reabsorption by either acute or chronic respiratory acidosis and, except at low delivery rates, no signifcant reduction in bicarbonate reabsorption by respiratory alkalosis.

\section{Methods}

All studies were carried out on male Munich-Wistar rats obtained from Simonsen Laboratories (Gilroy, CA). The rats were fed a normal protein, sodium- and potassium-free low bulk diet (ICN Nutritional Biochemicals, Cleveland, $\mathrm{OH}$ ), to which we added $2.0 \mathrm{mmol} \mathrm{NaCl}$ and 2 $\mathrm{mmol} \mathrm{KCl}$ per $12 \mathrm{~g}$ of diet, for 3-7 d before study. Rats were given food and water ad lib. After appropriate adaptation, the rats were prepared for micropuncture as described previously from our laboratory $(3,21)$. During surgery, to achieve euvolemia, most rats received a volume of plasma over $1 \mathrm{~h}$ equivalent to $1.3 \%$ of body wt from littermates exposed to the same prestudy conditions (22). The remaining animals were plasma expanded with a total volume equal to $3 \%$ body wt of plasma plus 3\% body wt of isohydric Ringer's solution over a 90-min period. In the euvolemic protocol, plasma was infused throughout the experiment at a rate sufficient to maintain hematocrit constant (8-12 $\mu \mathrm{l} /$ $\mathrm{min})$. In the plasma expansion protocol, rats received a 1:1 mixture of plasma and Ringer's solution ( $25 \mathrm{mM} \mathrm{NaHCO}, 110 \mathrm{mM} \mathrm{NaCl}, 5 \mathrm{mM}$ $\mathrm{KCl}$ ) throughout the experiment at a rate sufficient to maintain volume expansion and to keep plasma protein concentration constant (4). All blood removed for analysis was replaced by whole blood from littermate donors. For assessment of glomerular filtration rate (GFR), single-nephron GFR (SNGFR), and fluid reabsorption by the proximal tubule, a bolus injection of dialyzed [methoxy- ${ }^{3} \mathrm{H}$ ] inulin (DuPont NEN Research Products, Boston, MA) was given in Ringer's solution followed by a constant infusion at $0.84 \mathrm{ml} / \mathrm{h}$ (17). The inulin infusion was begun at least $45 \mathrm{~min}$ before beginning measurements. 


\section{Experimental protocols}

Acute respiratory acidosis (ARACID).' ARACID was induced following tracheostomy, by ventilating the rats on a small animal ventilator (Harvard Apparatus Co., Inc., The Ealing Corp., Millis, MA) with either an 8 or a $10 \% \mathrm{CO}_{2}$ (balance room air) gas mixture bubbled through water at room temperature. Oxygen was added to the inspired gas in an amount sufficient to maintain arterial $\mathrm{Po}_{2}$ at $\sim 100 \mathrm{mmHg}$. Nine ARACID rats were studied under euvolemic conditions and four were studied after plasma expansion. Potassium was removed from the Ringer's infusion during plasma expansion because acute hypercapnia induced an increase in plasma $\left[\mathrm{K}^{+}\right]$.

Chronic respiratory acidosis (CRACID). CRACID was induced by exposing rats to a $10 \% \mathrm{CO}_{2}$ (balance room air) atmosphere in an environmental chamber for 4-5 d. The $10 \% \mathrm{CO}_{2}$ mixture was obtained by mixing $100 \% \mathrm{CO}_{2}$ (bubbled through water at room temperature) with room air at ambient humidity. Gas samples from the chamber were measured using a Fyrite gas analyzer (Bacharach Inc., Pittsburgh, PA) to ensure that atmospheric $\mathrm{CO}_{2}$ in the chamber was constant. On the day of micropuncture the animal was injected with Inactin $(100 \mathrm{mg} / \mathrm{kg})$ and placed in a smaller chamber flooded with the same $10 \% \mathrm{CO}_{2}$ gas mixture. When anesthetized, the rat was weighed, a mask delivering $10 \% \mathrm{CO}_{2}$ and additional $\mathrm{O}_{2}$ was placed around the snout, and a tracheostomy was quickly performed. The rat was then ventilated with the $10 \% \mathrm{CO}_{2}$ gas mixture, again with added $\mathrm{O}_{2}$ to maintain arterial $\mathrm{PO}_{2}$ at $\sim 100 \mathrm{mmHg}$. All CRACID rats were studied under euvolemic conditions.

Acute respiratory alkalosis (ARALK). ARALK was induced after tracheostomy, by hyperventilating the anesthetized rats with a room air- $\mathrm{O}_{2}$ mixture bubbled through water at room temperature and adjusted to maintain arterial $\mathrm{PO}_{2}$ at $\sim 100 \mathrm{mmHg}$. All ARALK rats were studied under euvolemic conditions.

Chronic respiratory alkalosis (CRALK). CRALK was induced by exposing rats to a $12-14 \% \mathrm{O}_{2}$ (balance nitrogen) atmosphere in an environmental chamber for $24 \mathrm{~h}$ followed by $10-11 \% \mathrm{O}_{2}$ for an additional $3 \mathrm{~d}$. The low $\mathrm{O}_{2}$ mixture delivered to the chamber was obtained by mixing $100 \%$ nitrogen (bubbled through water at room temperature) with room air at ambient humidity. Gas samples from the chamber were measured using a Fyrite gas analyzer to insure that the low oxygen atmosphere was constant. On the day of micropuncture the animal was injected with Inactin and placed in a small chamber flooded with the same $10-11 \% \mathrm{O}_{2}$ gas mixture. When anesthetized, the rat was weighed and a tracheostomy was quickly performed. The rat was then hyperventilated with a room air- $\mathrm{O}_{2}$ mixture bubbled through water at room temperature and adjusted to maintain arterial $\mathrm{Po}_{2}$ at $\sim 100 \mathrm{mmHg}$. Two rats were studied under euvolemic conditions. The remaining seven were studied after plasma expansion to achieve filtered bicarbonate levels comparable to euvolemic normocapneic rats.

To assure that the level of ventilation during micropuncture in CRALK animals was comparable to the level induced by hypoxemia, $\mathrm{Pa}_{\mathrm{CO}_{2}}$ was measured in two awake rats after exposure to $10-11 \% \mathrm{O}_{2}$ for 4 d. Arterial blood gas measurements were obtained via a femoral catheter in these animals after $4.5 \mathrm{~h}$ in a holding chamber containing the same $10-11 \% \mathrm{O}_{2}$ atmosphere. $\mathrm{Pa}_{\mathrm{co}_{2}}$ averaged $27.1 \mathrm{mmHg}$ in these rats, a value similar to that produced during micropuncture (Table I). $\mathrm{Pa}_{\mathrm{O}_{2}}$ averaged $29.6 \mathrm{mmHg}$. As noted earlier, $\mathrm{Pa}_{\mathrm{O}_{2}}$ was deliberately raised to normal levels during the micropuncture measurements.

Normocapneic rats. Data for animals without respiratory acid-base disturbances, but with comparable filtered loads of bicarbonate $\left(\mathrm{FL}_{\mathrm{HCO}_{3}}\right.$ ), were obtained in 12 contemporaneously studied two-kidney euvolemic rats, as well as in $\mathbf{3 5}$ two-kidney rats from previous studies

1. Abbreviations used in this paper: $\mathrm{APR}_{\mathrm{HCO}_{3}}$, proximal bicarbonate reabsorption; ARACID, acute respiratory acidosis; ARALK, acute respiratory alkalosis; $B_{0}$, initial blood obtained after anesthesia; CRACID, chronic respiratory acidosis; CRALK, chronic respiratory alkalosis; $\mathrm{FL}_{\mathrm{HCO}_{3}}$, filtered load of bicarbonate.
(3-6). No differences in proximal bicarbonate reabsorption $\left(\mathrm{APR}_{\mathrm{HCO}_{3}}\right)$ were noted, for any given filtered load, when the new studies were compared with our previous studies. Therefore the new and old observations were pooled for comparison with rats with respiratory acidosis and alkalosis. To compare reabsorption at similar $\mathrm{FL}_{\mathrm{HCO}_{3}}$ values, the normocapneic animals include hydropenic, euvolemic, and plasma expanded rats. For any given range of $\mathrm{FL}_{\mathrm{HCO}_{3}}$, data from these protocols have also been pooled, because we showed previously that changes in plasma volume in the absence of major changes in plasma protein concentration had no delivery-independent effect on $\mathrm{APR}_{\mathrm{HCO}_{3}}$ (4). To evaluate the influence of $\mathrm{FL}_{\mathrm{HCO}_{3}}$ in hypercapneic rats with $\mathrm{FL}_{\mathrm{HCO}_{3}}$ $>2,000 \mathrm{pmol} / \mathrm{min}$, we used data from 13 remnant kidney rats (6), and 4 additional remnant kidney rats on a normal protein diet not previously reported. Although proximal tubular hypertrophy occurs in the functioning nephrons of the remnant kidney, we found no effect of hypertrophy on the relationship between delivery and reabsorption in these animals, at any given distance from Bowman's space, when compared with plasma-expanded two-kidney rats (6).

\section{Measurements}

Early, mid, and late proximal tubules (from different nephrons) were identified and mapped following either a small $(0.02 \mathrm{ml})$ jugular vein injection of lissamine green (10\%) dissolved in 5\% dextrose solution, or by visual assessment following intratubular injection of a small oil droplet. After injection of an oil block, timed (4-8 min) collections were then obtained from these sites as well as from Bowman's space for measurements of SNGFR, $\mathrm{FL}_{\mathrm{HCO}_{3}}$, and fluid and bicarbonate reabsorption, as described previously $(3,21)$. The micropuncture site was marked with a nigrosine-containing saline solution, the tubules subsequently microdissected after $\mathrm{HCl}$ digestion of the kidney, and the distance between the glomerulus and the site of puncture measured with an eyepiece micrometer. The distance from the glomerulus to the end of the convoluted portion of the proximal tubule was also measured using the same technique. Multiple blood and timed urine samples were collected during the experiment for measurement of arterial $\mathrm{pH}$, $\mathrm{Pa}_{\mathrm{CO}_{2}}, \mathrm{PO}_{2}$, plasma potassium and ${ }^{3} \mathrm{H}$ activity, urine ${ }^{3} \mathrm{H}$ activity, and total $\mathrm{CO}_{2}$ excretion.

\section{Analytical methods, calculations, and statistics}

Blood $\mathrm{pH}, \mathrm{Pa}_{\mathrm{CO}_{2}}$, and $\mathrm{Pa}_{\mathrm{O}_{2}}$ were measured using a Radiometer blood gas analyzer (Radiometer, Copenhagen, Denmark). Plasma bicarbonate concentration was calculated using the Henderson-Hasselbalch equation. Plasma potassium concentration was measured by flame photometry. SNGFR and proximal reabsorption rates were calculated using standard formulas. Tubule fluid bicarbonate concentrations (assumed to equal the measured total $\mathrm{CO}_{2}$ concentration [21]) were determined by microcalorimetry (23). $\mathrm{FL}_{\mathrm{HCO}_{3}}$ was calculated from the product of SNGFR and Bowman's space concentration of bicarbonate. The relationships between reabsorption and distance from Bowman's space shown in Figs. 1-3 were fitted to an empirically chosen hyperbolic curve of the form $y=a x /(b+x)$, using a computer-based nonlinear least-squares search (24). Statistical analyses of results were carried out by unpaired analysis of variance, and by a residual sum of squares method for comparing nonlinear relationships (24).

\section{Results}

General. Table I presents the weights, blood pressures, hematocrits, and plasma composition of the study groups. The normocapneic rats shown in the table include 12 euvolemic two-kidney rats and 4 euvolemic remnant kidney rats not previously reported. CRACID and CRALK rats had lower body weights than did the normocapneic rats. Hematocrit was slightly lower in the remnant kidney rats, and slightly higher in the CRACID and CRALK rats. Of note, the first hematocrit obtained after induction of anesthesia was higher both in CRACID and 
Table I. General Characteristics and Arterial Blood Composition

\begin{tabular}{|c|c|c|c|c|c|c|c|c|c|c|}
\hline \multirow[b]{2}{*}{ Group } & \multirow[b]{2}{*}{ BWt } & \multirow[b]{2}{*}{ AP } & \multirow{2}{*}{$\begin{array}{l}\text { Expt } \\
\text { Het }\end{array}$} & \multicolumn{2}{|c|}{ Plasma $\left[K^{+}\right]$} & \multirow[b]{2}{*}{$\mathrm{pH}$} & \multirow[b]{2}{*}{$\mathrm{Pa}_{\mathrm{CO}_{2}}$} & \multirow[b]{2}{*}[\mathrm{HCO}_{3}^{-}]{} & \multicolumn{2}{|c|}{ Plasma [protein] } \\
\hline & & & & $\mathbf{B}_{0}$ & Expt & & & & $\mathbf{B}_{\mathbf{0}}$ & Expt \\
\hline & $g$ & $m m H g$ & vol\% & \multicolumn{2}{|c|}{$m M$} & & $m m H g$ & $m M$ & \multicolumn{2}{|c|}{$g / d l$} \\
\hline \multicolumn{11}{|l|}{ Normocapneic rats } \\
\hline \multirow[t]{2}{*}{ Two-kidney (12) } & 271 & 113 & 48.9 & 4.68 & $4.42^{*}$ & 7.45 & 42.2 & 28.3 & 5.8 & $5.6^{*}$ \\
\hline & \pm 6 & \pm 2 & \pm 0.8 & \pm 0.10 & \pm 0.06 & \pm 0.01 & \pm 0.7 & \pm 0.4 & \pm 0.05 & \pm 0.08 \\
\hline \multirow[t]{2}{*}{ Remnant (4) } & 266 & 121 & $44.1^{\ddagger}$ & $3.73^{\ddagger}$ & $3.75^{\ddagger}$ & 7.46 & 37.4 & $25.8^{\ddagger}$ & 5.7 & 5.8 \\
\hline & \pm 9 & \pm 1 & \pm 0.7 & \pm 0.12 & \pm 0.10 & \pm 0.01 & \pm 0.2 & \pm 0.5 & \pm 0.17 & \pm 0.10 \\
\hline \multicolumn{11}{|l|}{ Hypercapneic rats } \\
\hline \multirow[t]{2}{*}{ ARACID (13) } & 259 & $106^{\ddagger 5}$ & $48.0^{8}$ & $4.66^{8}$ & $5.04^{\neq \$ *}$ & $7.23^{\ddagger \S}$ & $74.5^{\ddagger \S}$ & $30.5^{\$ \S}$ & 5.9 & 5.8 \\
\hline & \pm 4 & \pm 2 & \pm 0.7 & \pm 0.08 & \pm 0.10 & \pm 0.01 & \pm 1.6 & \pm 0.6 & \pm 0.08 & \pm 0.08 \\
\hline \multirow[t]{2}{*}{ CRACID (6) } & $249^{\ddagger}$ & $104^{8}$ & $51.9^{\ddagger \$ ॥}$ & $4.56^{8}$ & $4.58^{811}$ & $7.31^{\neq \$ 11}$ & $84.0^{\ddagger \$ ॥}$ & $41.0^{\ddagger \$ 11}$ & \pm 5.7 & $5.3^{511 *}$ \\
\hline & \pm 8 & \pm 3 & \pm 1.1 & \pm 0.09 & \pm 0.11 & \pm 0.01 & \pm 1.7 & \pm 1.0 & \pm 0.11 & \pm 0.11 \\
\hline \multicolumn{11}{|l|}{ Hypocapneic rats } \\
\hline \multirow[t]{2}{*}{ ARALK (7) } & 263 & 111 & $48.6^{51}$ & $4.67^{\S}$ & $4.04^{\mp 111 \%}$ & $7.56^{\text {+\$11 }}$ & $29.3^{\text {\$\$|1 }}$ & $25.7^{\ddagger \text { מוֹ }}$ & 5.9 & $5.8^{\prime}$ \\
\hline & \pm 6 & \pm 3 & \pm 0.5 & \pm 0.11 & \pm 0.04 & \pm 0.01 & \pm 0.4 & \pm 0.4 & \pm 0.09 & \pm 0.04 \\
\hline \multirow[t]{2}{*}{ CRALK (9) } & $227^{+8 \mid 11 * * *}$ & $109^{\S}$ & $52.5^{\ddagger \xi \xi 1 * *}$ & $4.70^{\S}$ & $4.10^{ \pm 117 *}$ & $7.54^{\text {t\$|1 }}$ & $25.9^{\ddagger 5 \mid 11}$ & $21.2^{\ddagger \xi|| 1 * * *}$ & 5.9 & $5.9^{ \pm 1}$ \\
\hline & \pm 4 & \pm 2 & \pm 1.0 & \pm 0.14 & \pm 0.11 & \pm 0.02 & \pm 1.2 & \pm 0.6 & \pm 0.11 & \pm 0.11 \\
\hline
\end{tabular}

Number in parentheses is the number of animals; $\mathrm{BWt}$, body wt; AP, mean arterial blood pressure; Hct, mean experimental hematocrit; $\mathrm{pH}$, $\mathrm{Pa}_{\mathrm{CO}_{2}}$, and $\left[\mathrm{HCO}_{3}^{-}\right]$, mean values for systemic arterial $\mathrm{pH}, \mathrm{P}_{\mathrm{CO}}$, and bicarbonate concentration, respectively. ${ }^{*} P<0.05$ vs. $\mathrm{B}_{0}$ value. ${ }^{\ddagger} P$ $<0.05$ vs. two-kidney. ${ }^{\$} P<0.05$ vs. remnant. $" P<0.05$ vs. ARACID. ${ }^{\prime} P<0.05$ vs. CRACID. ${ }^{* *} P<0.05$ vs. ARALK.

CRALK (56.0 \pm 0.5 and $64.8 \pm 0.2$ vol \%, respectively) as compared with the other groups. These values were brought down toward the levels in the other groups by plasma infusion before micropuncture. Plasma protein concentrations were similar in all groups in the initial blood obtained after anesthesia $\left(B_{0}\right)$. During plasma and fluid infusion, protein concentration fell slightly in normocapnia and CRACID. Plasma $\left[\mathrm{K}^{+}\right]$was similar in all groups, except for remnant kidney rats, in the $B_{0}$ blood, but increased during induction of ARACID, and fell both in ARALK and CRALK. Arterial blood acid-base parameters demonstrated the expected changes (Table I). No bicarbonate diuresis was noted in any group. Fractional bicarbonate reabsorption (whole kidney) was $>99 \%$ both in normocapneic and experimental animals.

Proximal bicarbonate reabsorption. Table II presents the mean values for $\mathrm{FL}_{\mathrm{HCO}_{3}}$ and $\mathrm{APR}_{\mathrm{HCO}_{3}}$ obtained from collections in the early (0.5-1.5 mm from Bowman's space) and late (last loop or $\geq 4.5 \mathrm{~mm}$ from Bowman's space) proximal tubule in all animals studied under euvolemic conditions. When evaluated in this manner, CRACID significantly increased both early and overall proximal $\mathrm{HCO}_{3}$ reabsorption as compared with euvolemic normocapneic animals, and ARACID increased overall proximal reabsorption. ARALK had no significant effect. In the few observations we made under euvolemic conditions, CRALK appears to decrease early and overall proximal reabsorption. Although these changes suggest that respiratory acidosis and alkalosis influence reabsorption, it should be noted that the changes observed in $\mathrm{APR}_{\mathrm{HCO}_{3}}$ are all mirrored by parallel changes in $\mathrm{FL}_{\mathrm{HCO}_{3}}$. As shown in Table II, $\mathrm{FL}_{\mathrm{HCO}_{3}}$ changed significantly in all settings in which $\mathrm{APR}_{\mathrm{HCO}_{3}}$ changed. Because delivery is known to influence proximal reabsorption in the absence of changes in $\mathrm{Pa}_{\mathrm{Co}_{2}}(3-8)$, we sought to control for this influence by subdividing our observations in respiratory acidosis and alkalosis over several ranges of $\mathrm{FL}_{\mathrm{HCO}_{3}}$, and comparing them with normocapneic rats with the same $\mathrm{FL}_{\mathrm{HCO}_{3}}$.

Acute respiratory acidosis. In this disorder we subdivided our observations into three ranges of $\mathrm{FL}_{\mathrm{HCO}_{3}}(1,200-1,600$, $1,600-2,000$, and $2,100-2,500 \mathrm{pmol} / \mathrm{min})$. The range $2,100-$ $2,500 \mathrm{pmol} / \mathrm{min}$ was used rather than $2,000-2,400 \mathrm{pmol} / \mathrm{min}$ because $\mathrm{FL}_{\mathrm{HCO}_{3}}$ differed slightly between normocapneic and hypercapneic animals in the latter range. Table III summarizes the mean $\mathrm{FL}_{\mathrm{HCO}_{3}}$ and SNGFR values for the normocapneic and ARACID animals in each range. In the lower two ranges, the normocapneic animals are normal rats studied either under euvolemic conditions or after acute plasma expansion. In the highest $\mathrm{FL}_{\mathrm{HCO}_{3}}$ range $(2,100-2,500 \mathrm{pmol} / \mathrm{min})$, the normocapneic rats are primarily remnant kidney animals in which $\mathrm{FL}_{\mathrm{HCO}_{3}}$ was increased by the high SNGFR levels achieved. Because we have grouped animals with comparable $\mathrm{FL}_{\mathrm{HCO}_{3}}$ values, mean SNGFR at each level of $\mathrm{FL}_{\mathrm{HCO}_{3}}$ is, by definition, lower in ARACID as compared with normocapnia, because of the higher plasma $\left[\mathrm{HCO}_{3}^{-}\right]$.

Proximal bicarbonate reabsorption in ARACID is compared with normocapnia in Fig. 1 and Table IV. In each panel of Fig. 1, bicarbonate reabsorption is plotted as a function of distance from Bowman's space in millimeters for a range of values for $\mathrm{FL}_{\mathrm{HCO}_{3}}$. The hatched area in each plot represents the 95\% confidence bands for the observations in normocapneic rats. The regression equation values and $\mathrm{F}$ test comparisons are presented in Table IV. At the lowest range of $\mathrm{FL}_{\mathrm{HCO}_{3}}(1,200-$ $1,600 \mathrm{pmol} / \mathrm{min}$ ), early proximal bicarbonate reabsorption is at the lower end of the normocapnia confidence bands (Fig. 1 $A)$, and the regression equation is significantly different $(P$ $<0.025)$. In the mid-range $(1,600-2,000 \mathrm{pmol} / \mathrm{min})$, both early and overall proximal reabsorption are reduced $(P<0.01)$. 
Table II. Effect of Respiratory Acid-Base Disorders on Reabsorption at Early and Late Proximal Tubular Sites in Euvolemic Rats

\begin{tabular}{|c|c|c|c|c|c|c|}
\hline & \multicolumn{3}{|c|}{ Early proximal tubule } & \multicolumn{3}{|c|}{ Late proximal tubule } \\
\hline & $\mathrm{FL}_{\mathrm{HCO}_{3}}$ & $\mathrm{APR}_{\mathrm{HCO}_{3}}$ & $\begin{array}{l}\text { Distance from } \\
\text { Bowman's space }\end{array}$ & $\mathrm{FL}_{\mathrm{HCO}_{3}}$ & $\mathrm{APR}_{\mathrm{HCO}_{3}}$ & $\begin{array}{l}\text { Distance from } \\
\text { Bowman's space }\end{array}$ \\
\hline & \multicolumn{2}{|c|}{$\mathrm{pmol} / \mathrm{min}$} & $m m$ & \multicolumn{2}{|c|}{$\mathrm{pmol} / \mathrm{min}$} & $m m$ \\
\hline \multirow[t]{3}{*}{ Normocapnia } & 1,238 & 487 & 0.93 & 1,282 & 1,117 & 5.48 \\
\hline & \pm 64 & \pm 36 & \pm 0.07 & \pm 43 & \pm 37 & \pm 0.16 \\
\hline & (20) & (20) & $(20)$ & $(43)$ & $(43)$ & $(33)$ \\
\hline \multirow[t]{3}{*}{ ARACID } & 1,475 & 603 & 1.15 & $1,637^{*}$ & $1,297^{*}$ & 5.66 \\
\hline & \pm 163 & \pm 117 & \pm 0.13 & \pm 94 & \pm 64 & \pm 0.20 \\
\hline & (7) & (7) & (7) & $(16)$ & $(16)$ & $(14)$ \\
\hline \multirow[t]{3}{*}{ CRACID } & $2,304^{* \pm}$ & $709 *$ & 1.14 & $2,143^{* \neq}$ & $1,404^{*}$ & 5.43 \\
\hline & \pm 160 & \pm 45 & \pm 0.08 & \pm 133 & \pm 80 & \pm 0.21 \\
\hline & (12) & $(12)$ & $(12)$ & (11) & $(11)$ & $(11)$ \\
\hline \multirow[t]{3}{*}{ ARALK } & $1,193^{8}$ & $490^{8}$ & 1.06 & $1,211^{\ddagger \S}$ & $1,002^{\ddagger 5}$ & 5.34 \\
\hline & \pm 98 & \pm 56 & \pm 0.09 & \pm 131 & \pm 108 & \pm 0.25 \\
\hline & (9) & (9) & (9) & (11) & (11) & $(11)$ \\
\hline \multirow[t]{3}{*}{ CRALK } & $566^{* \pm \$ ॥}$ & $243^{* \neq \S}$ & 0.88 & 631 & 449 & 5.25 \\
\hline & \pm 58 & \pm 43 & \pm 0.19 & & & \\
\hline & (3) & (3) & (3) & (1) & (1) & (1) \\
\hline
\end{tabular}

Number in parentheses is the number of collections. Early proximal tubule, all collections $0.5-1.5 \mathrm{~mm}$ from Bowman's space; late proximal tubule, all collections $\geq 4.5 \mathrm{~mm}$ from Bowman's space or last loop of proximal convoluted tubule. ${ }^{*} P<0.05$ vs. normocapnia. ${ }^{\ddagger} P<0.05$ vs. ARACID. ${ }^{8} P<0.05$ vs. CRACID. " $P<0.05$ vs. ARALK.

At the highest range $(2,100-2,500 \mathrm{pmol} / \mathrm{min})$, bicarbonate reabsorption in ARACID is not significantly different from normocapnia.

Chronic respiratory acidosis. In this disorder we subdivided our observations into two ranges of $\mathrm{FL}_{\mathrm{HCO}_{3}}(1,600-2,000$, and $2,100-2,500 \mathrm{pmol} / \mathrm{min})$. Table III summarizes the mean $\mathrm{FL}_{\mathrm{HCO}_{3}}$ and SNGFR values for each range. Again, because we have grouped animals with comparable $\mathrm{FL}_{\mathrm{HCO}_{3}}$ values, mean SNGFR is significantly lower in CRACID than in normocapnia at each $\mathrm{FL}_{\mathrm{HCO}_{3}}$ range, due to the higher bicarbonate concentration in the CRACID animals. As can be seen in Fig. $1 B$ and Table IV, no significant difference in the pattern of bicarbonate reabsorption was seen in CRACID as compared with normocapnia in the $1,600-2,000$ range. In the higher range $(C)$, the pattern of early proximal bicarbonate reabsorption is identical to that seen in remnant kidney rats, but reabsorption at late proximal tubule sites fell slightly below that seen in the remnants. As a result, comparison of the curves showed a significant difference (Table IV).
Acute respiratory alkalosis. In this disorder, we subdivided our observations into three ranges of $\mathrm{FL}_{\mathrm{HCO}_{3}}(800-1,000$, $1,000-1,200$, and $1,200-1,400 \mathrm{pmol} / \mathrm{min})$. Table $\mathrm{V}$ presents the mean $\mathrm{FL}_{\mathrm{HCO}_{3}}$ values for each range. Because bicarbonate concentration is slightly lower than normocapnia in this group, SNGFR is higher than normocapnia in the two higher $\mathrm{FL}_{\mathrm{HCO}_{3}}$ ranges, although the difference is small $(44.3 \pm 0.9$ vs. $40.7 \pm 0.5$ $\mathrm{nl} / \mathrm{min}$ at the highest range). Reabsorption along the proximal tubule in ARALK for each range of $\mathrm{FL}_{\mathrm{HCO}_{3}}$ is shown in Fig. 2, and the equations and comparisons are shown in Table IV. In this disorder, no changes in bicarbonate reabsorption were noted as compared with normocapneic rats at any level of bicarbonate delivery.

Chronic respiratory alkalosis. In this disorder, we subdivided our observations into three ranges of $\mathrm{FL}_{\mathrm{HCO}_{3}}(600-800$, $800-1,000$, and $1,000-1,200 \mathrm{pmol} / \mathrm{min})$. To attain the higher delivery rates, plasma expansion was required. Table $\mathrm{V}$ presents the mean $\mathrm{FL}_{\mathrm{HCO}_{3}}$ and SNGFR values for each range. Because bicarbonate concentration was lower in CRALK than in

Table III. Filtered Load of Bicarbonate and Single Nephron GFR in Respiratory Acidosis

\begin{tabular}{|c|c|c|c|c|c|c|c|c|c|}
\hline & \multicolumn{3}{|c|}{$1,200-1,600$} & \multicolumn{3}{|c|}{$\begin{array}{c}\text { Filtered load range } \\
\text { pmol } / \mathrm{min} \\
1,600-2,000\end{array}$} & \multicolumn{3}{|c|}{$2,100-2,500$} \\
\hline & $n$ & $\mathrm{FL}_{\mathrm{HCO}_{3}}{ }^{*}$ & SNGFR $^{\ddagger}$ & $n$ & $\mathrm{FL}_{\mathrm{HCO}}$ & SNGFR & $n$ & $\mathrm{FL}_{\mathrm{HCO}_{3}}$ & SNGFR \\
\hline Normocapnia & 57 & $1,390 \pm 15$ & $37.7 \pm 0.4$ & 18 & $1,775 \pm 24$ & $54.8 \pm 1.0$ & $17^{\S}$ & $2,273 \pm 23$ & $75.4 \pm 1.9$ \\
\hline ARACID & 18 & $1,398 \pm 27$ & $35.0 \pm 0.7^{11}$ & 21 & $1,790 \pm 24$ & $51.1 \pm 1.0^{\prime}$ & 13 & $2,265 \pm 36$ & $60.0 \pm 1.1^{11}$ \\
\hline CRACID & & - & - & 5 & $1,860 \pm 50$ & $40.4 \pm 1.9^{11 * *}$ & 14 & $2,327 \pm 30$ & $49.5 \pm 0.9^{11 * *}$ \\
\hline
\end{tabular}

$n$, number of tubular fluid collections. ${ }^{*}$ pmol/min. ${ }^{\ddagger} \mathrm{nl} / \mathrm{min} .{ }^{8} \mathrm{FL}_{\mathrm{HCO}_{3}}>2,000$; controls include 2 normal and 15 remnant kidney rats. " $P$ $<0.01$ vs. normocapnia. ' $P<0.025$ vs. normocapnia. ${ }^{* *} P<0.01$ vs. ARACID. 


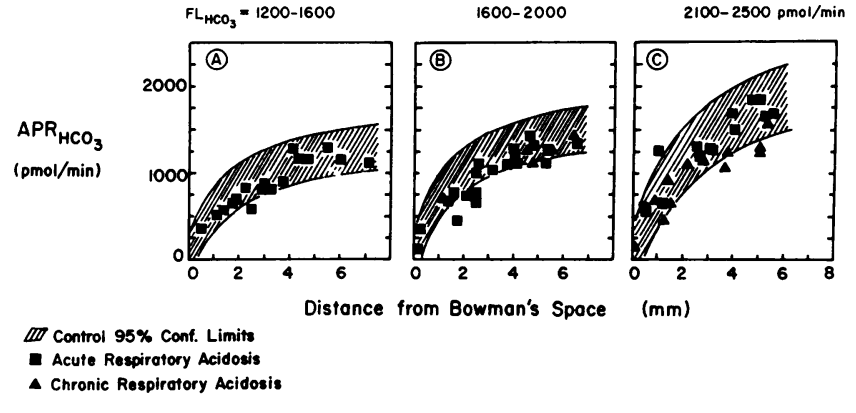

Figure 1. $\mathrm{APR}_{\mathrm{HCO}_{3}}$ as a function of distance from Bowman's space in rats with acute and chronic respiratory acidosis. Data are subdivided into three groups according to $\mathrm{FL}_{\mathrm{HCO}_{3}}$ in pmol/min: $(A) 1,200-1,600$; (B) $1,600-2,000 ;(C) 2,100-2,500$. The nonlinear equations used to develop the confidence bands for the normocapneic animals (control) and to compare normocapnia and hypercapnia are presented in Table IV. The confidence bands encompass the maximal tubule length measured in normocapneic animals at each $\mathrm{FL}_{\mathrm{HCO}_{3}}$ range, except for $C$ where the maximal tubule length $(9 \mathrm{~mm})$ extended far beyond the experimental observations.

normocapnia, SNGFR values were higher at each $\mathrm{FL}_{\mathrm{HCO}_{3}}$ range in the CRALK animals. The pattern of proximal bicarbonate reabsorption is shown in Fig. 2 for all three $\mathrm{FL}_{\mathrm{HCO}_{3}}$ ranges, and the equations and comparisons are presented in Table IV. At the lowest range, $600-800 \mathrm{pmol} / \mathrm{min}$ (Fig. $2 \mathrm{~A}$ ), overall proximal bicarbonate reabsorption was significantly decreased in CRALK, but insufficient data are available to assess reabsorption in the early proximal tubule. At higher filtered loads $(800-1,000,1,000-1,200 \mathrm{pmol} / \mathrm{min})$, no significant re- duction in proximal bicarbonate reabsorption was seen as compared with normocapneic animals (Fig. 2, $B$ and $C$ ). In the mid-range (800-1,000 $\mathrm{pmol} / \mathrm{min})$, regression comparison showed a borderline significance $(P=0.05)$, suggesting an increase in reabsorption in CRALK. This comparison is influenced by one early proximal observation, and it is unlikely that any real difference is present.

\section{Discussion}

The results of this study indicate that, when changes in bicarbonate delivery are taken into account, no additional stimulation of bicarbonate reabsorption can be demonstrated in either acute or chronic respiratory acidosis, and no reduction in reabsorption is found with acute respiratory alkalosis. With chronic respiratory alkalosis, reabsorption is dampened, but only at low delivery rates. These results contrast with microperfusion studies in isolated segments of the proximal tubule that show a clear stimulation of reabsorption by increases in $\mathrm{P}_{\mathrm{CO}_{2}}$ and a clear reduction when $P_{\mathrm{Co}_{2}}$ is decreased $(11,12,14-16)$. Although such studies indicate that changes in $\mathrm{P}_{\mathrm{Co}_{2}}$ influence proximal bicarbonate reabsorption, they do not address the relative importance of this effect, as opposed to other influences such as bicarbonate delivery, under free-flow conditions. The relationship of our findings to previous studies is discussed separately below for each respiratory acid-base disorder.

Respiratory acidosis. Bicarbonate reabsorption in the early proximal tubule has not previously been examined under freeflow conditions in acute respiratory acidosis, but our results are consistent with previous micropuncture studies of end-proximal reabsorption in this disorder (18-20). All studies to date

Table IV. Regression Equations and Comparisons

\begin{tabular}{|c|c|c|c|c|c|c|c|c|}
\hline & \multirow[b]{2}{*}{$\mathrm{FL}_{\mathrm{HCO}_{3}}$} & \multirow[b]{2}{*}{ Group } & \multicolumn{4}{|c|}{ Coefficients } & \multirow[b]{2}{*}{$P$ value } & \multirow[b]{2}{*}{ Comment } \\
\hline & & & $a$ & $b$ & $r$ & $n$ & & \\
\hline & pmols/min & & & & & & & \\
\hline \multirow[t]{8}{*}{ Respiratory acidosis } & $1,200-1,600$ & Normocapnia & 1,600 & 1.75 & 0.92 & 57 & & \\
\hline & & ARACID & 1,800 & 3.05 & 0.92 & 18 & $P<0.025$ & Reabsorption lower in ARACID \\
\hline & $1,600-2,000$ & Normocapnia & 1,860 & 1.60 & 0.96 & 18 & & \\
\hline & & ARACID & 2,110 & 3.37 & 0.93 & 21 & $P<0.01$ & Reabsorption lower in ARACID \\
\hline & & CRACID & 1,740 & 1.82 & 0.95 & 5 & $P>0.1$ & \\
\hline & $2,100-2,500$ & Normocapnia & 2,745 & 2.71 & 0.97 & 17 & & \\
\hline & & ARACID & 2,210 & 1.57 & 0.91 & 14 & $P>0.1$ & \\
\hline & & CRACID & 1,980 & 2.15 & 0.93 & 13 & $P<0.01$ & Reabsorption lower in CRACID \\
\hline \multirow[t]{10}{*}{ Respiratory alkalosis } & $600-800$ & Normocapnia & 830 & 1.39 & 0.96 & 13 & & \\
\hline & & CRALK & 770 & 2.21 & 0.80 & 13 & $P<0.01$ & Reabsorption lower in CRALK \\
\hline & $800-1,000$ & Normocapnia & 1,110 & 1.84 & 0.94 & 17 & & \\
\hline & & CRALK & 720 & 0.37 & 0.81 & 16 & $P=0.05$ & Reabsorption higher in CRALK \\
\hline & & ARALK & 880 & 1.10 & 0.75 & 6 & $P>0.1$ & \\
\hline & $1,000-1,200$ & Normocapnia & 1,320 & 1.97 & 0.94 & 42 & & \\
\hline & & CRALK & 1,080 & 1.03 & 0.94 & 7 & $P>0.1$ & \\
\hline & & ARALK & 1,350 & 2.42 & 0.92 & 17 & $P>0.1$ & \\
\hline & $1,200-1,400$ & Normocapnia & 1,570 & 1.93 & 0.90 & 30 & & \\
\hline & & ARALK & 1,570 & 2.21 & 0.94 & 11 & $P>0.1$ & \\
\hline
\end{tabular}

$n$, number of tubule fluid collections; $r$, correlation coefficient. Equation used: $A P R_{\mathrm{HCO}_{3}}=a x /(b+x)$ where $x=$ distance from glomerulus in millimeters. 
Table V. Filtered Load of Bicarbonate and Single Nephron GFR in Respiratory Alkalosis

\begin{tabular}{|c|c|c|c|c|c|c|c|c|c|c|c|c|}
\hline & \multicolumn{12}{|c|}{$\begin{array}{l}\text { Filtered load range } \\
\text { pmol/min }\end{array}$} \\
\hline & \multicolumn{3}{|c|}{$600-800$} & \multicolumn{3}{|c|}{$800-1,000$} & \multicolumn{3}{|c|}{$1,000-1,200$} & \multicolumn{3}{|c|}{$1,200-1,400$} \\
\hline & $n$ & $\mathrm{FL}_{\mathrm{HCO}_{3}}{ }^{*}$ & SNGFR $^{\ddagger}$ & $n$ & $\mathrm{FL}_{\mathrm{HCO}_{3}}$ & SNGFR & $n$ & $\mathrm{FL}_{\mathrm{HCO}_{3}}$ & SNGFR & $n$ & $\mathrm{FL}_{\mathrm{HCO}_{3}}$ & SNGFR \\
\hline Normocapnia & 13 & $726 \pm 16$ & $24.4 \pm 0.6$ & 17 & $906 \pm 15$ & $30.4 \pm 0.5$ & 42 & $1,100 \pm 10$ & $35.6 \pm 0.3$ & 30 & $1,304 \pm 10$ & $40.7 \pm 0.5$ \\
\hline ARALK & - & - & - & 6 & $912 \pm 32$ & $32.1 \pm 1.6$ & 17 & $1,112 \pm 12$ & $37.9 \pm 0.9^{\S}$ & 11 & $1,298 \pm 20$ & $44.3 \pm 0.9^{\prime \prime}$ \\
\hline CRALK & 13 & $688 \pm 15$ & $30.1 \pm 0.9^{\| 1}$ & 16 & $915 \pm 14$ & $36.7 \pm 0.8^{111}$ & 7 & $1,084 \pm 32$ & $41.6 \pm 2.1^{11 * *}$ & - & - & - \\
\hline
\end{tabular}

$n$, number of tubular fluid collections. ${ }^{*}$ pmol/min. ${ }^{\ddagger} \mathrm{nl} / \mathrm{min} .{ }^{8} P<0.025$ vs. normocapnia. $" I<0.01$ vs. normocapnia. ${ }^{\top} P<0.01$ vs. ARALK. ${ }^{* *} P<0.025$ vs. ARALK.

indicate that end-proximal bicarbonate reabsorption in the rat does not increase unless bicarbonate delivery is concomitantly increased. In our studies, bicarbonate reabsorption in the proximal tubule varied in direct relation to changes in $\mathrm{FL}_{\mathrm{HCO}_{3}}(\mathrm{Ta}-$ ble II, Fig. 1). In the lower $\mathrm{FL}_{\mathrm{HCO}_{3}}$ ranges, bicarbonate reabsorption actually fell slightly below that seen in normocapneic animals (Fig. 1, $A$ and $B$ ). The cause of this reduction is unclear, but could be related to hyperkalemia. In the lower two $\mathrm{FL}_{\mathrm{HCO}_{3}}$ ranges, virtually all the observations are from the euvolemic animals (mean plasma $\left[\mathrm{K}^{+}\right]=5.2 \pm 0.08 \mathrm{mM}$, lowest value $4.9 \mathrm{mM})$. In the highest range of $\mathrm{FL}_{\mathrm{HCO}_{3}}(2,100-2,500$ $\mathrm{pmol} / \mathrm{min}), 12$ of the 14 observations are from plasma expanded rats (mean plasma $\left[\mathrm{K}^{+}\right]=4.60 \pm 0.09 \mathrm{mM}, P<0.001$ as compared with euvolemic ARACID rats), and in these animals the pattern of reabsorption is not different from that seen in

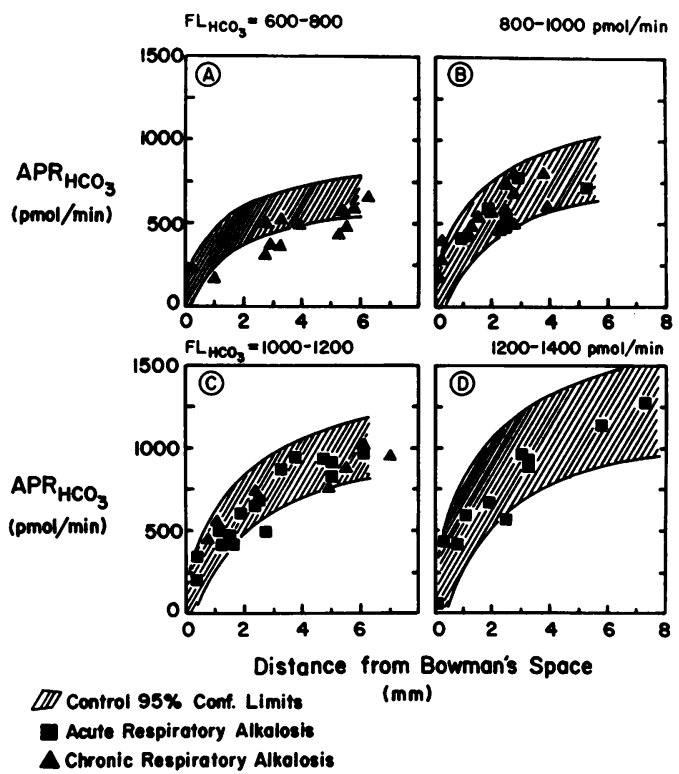

Figure 2. $\mathrm{APR}_{\mathrm{HCO}_{3}}$ as a function of distance from Bowman's space in rats with acute and chronic respiratory alkalosis. Data are subdivided into four groups according to $\mathrm{FL}_{\mathrm{HCO}_{3}}$ in pmol/min: $(A) 600-800 ;(B)$ $800-1,000 ;(C) 1,000-1,200$; (D) $1,200-1,400$. The nonlinear equations used to develop the confidence bands for the normocapneic animals (control) and to compare normocapnia and hypocapnia are presented in Table IV. The tubule length encompassed by the confidence bands extends to the longest tubule measured in the normocapneic rats in each $\mathrm{FL}_{\mathrm{HCO}_{3}}$ range.

normocapneic animals. At the highest levels of delivery, the reabsorptive rates in ARACID were not different from those seen in normocapneic rats with metabolic alkalosis (Fig. 3) or with remnant kidneys (Fig. 1).

In contrast to acute respiratory acidosis, an increase in endproximal bicarbonate reabsorption has been reported in freeflow micropuncture studies in chronic respiratory acidosis (25, 26). In these studies, however, reabsorption has been compared to normocapneic animals with a much lower $\mathrm{FL}_{\mathrm{HCO}_{3}}$. Our results are consistent with these previous observations. When CRACID rats are compared with euvolemic two-kidney rats with no acid-base disturbance, bicarbonate reabsorption both in the early and late proximal tubule is significantly increased (Table II). However, as shown in Table II, $\mathrm{FL}_{\mathrm{HCO}_{3}}$ in the normocapneic rats is only $54 \%$ of the value seen in the CRACID rats. When compared with rats with a similar $\mathrm{FL}_{\mathrm{HCO}_{3}}$ but without hypercapnia or acidemia, no stimulation of reabsorption is observed in the CRACID rats (Fig. 1). In fact, at the highest delivery rates $(2,100-2,500 \mathrm{pmol} / \mathrm{min})$, proximal bicarbonate reabsorption is lower in respiratory acidosis than in normocapneic remnant kidney rats. The rats in this latter group have proximal tubular hypertrophy (6), in contrast to the CRACID animals. Because we found no stimulation of bicarbonate reabsorption at any given distance from Bowman's space in remnant kidney rats compared with two-kidney plasma expanded rats at similar $\mathrm{FL}_{\mathrm{HCO}_{3}}$ values (6), it seems unlikely that tubular hypertrophy is responsible for the higher rate of reabsorption.

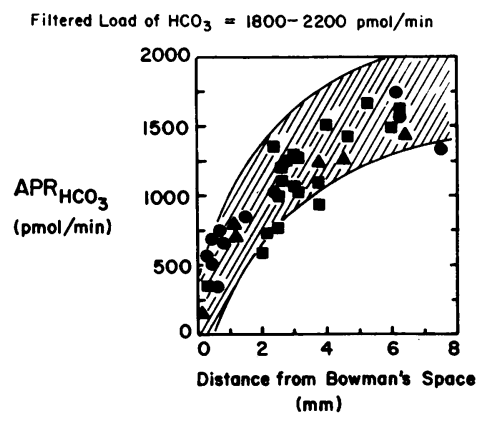

IID Control 95\% Conf. Limits

- Chronic Metabolic Alkalosis

- Acute Respirotory Acidosis

- Chronic Respiratory Acidosis
Figure 3. Comparison of $\mathrm{APR}_{\mathrm{HCO}_{3}}$ as a function of distance from Bowman's space in rats without acid-base disorders (control), rats with metabolic alkalosis, and rats with acute or chronic respiratory acidosis. To control for the deliverydependence of $\mathrm{APR}_{\mathrm{HCO}_{3}}$, observations are from rats with the same range of filtered bicarbonate, 1,800 $2,200 \mathrm{pmol} / \mathrm{min}$. The observations encompassed by the confidence bands are from normal and remnant kidney rats. The metabolic alkalosis observations are from reference 5 . 
The reason for the decrease in reabsorption at high delivery rates in chronic hypercapnia is unclear, but the finding is consistent with previous studies showing a decrease in fractional bicarbonate reabsorption in the late proximal tubule in this disorder (25).

It should be noted that the high $\mathrm{FL}_{\mathrm{HCO}_{3}}$ in the CRACID animals is due to a high plasma $\left[\mathrm{HCO}_{3}^{-}\right]$and in the normocapneic animals is due to a high SNGFR. In vivo microperfusion studies have shown that increased flow has a stimulatory effect on early proximal reabsorption independent of bicarbonate delivery, but only at bicarbonate delivery rates $<1,200 \mathrm{pmol} /$ min (10). Moreover, comparison of the pattern of proximal bicarbonate reabsorption in respiratory acidosis and chronic metabolic alkalosis argues against any major independent effect of flow rate at high bicarbonate delivery rates. In the latter disorder, rats have a normal $\mathrm{Pa}_{\mathrm{CO}_{2}}$, an alkaline $\mathrm{pH}$, and $\mathrm{FL}_{\mathrm{HCO}_{3}}$ is high because of a high plasma [ $\left.\mathrm{HCO}_{3}^{-}\right]$. In Fig. 3, we have plotted bicarbonate reabsorption as a function of distance from the glomerulus in rats with chronic metabolic alkalosis (5), and in rats with acute or chronic respiratory acidosis over a comparable range of $\mathrm{FL}_{\mathrm{HCO}_{3}}$ values (1,800-2,200 pmol/min). Tubule fluid flow rate (SNGFR) in chronic metabolic alkalosis was the same as in the CRACID rats. As can be seen, the pattern of reabsorption is indistinguishable in the three disorders, and no disorder is different from rats with normal acid-base status.

The bicarbonate reabsorptive rates that occur in the proximal tubule in response to high filtered loads (> 1,400 pmols/ min) cannot be accounted for on a physicochemical basis ( 7 , 8 ), and thus one must invoke an increase in the number or activity of epithelial proton transporters and/or basolateral bicarbonate transporters. The major stimulus for this increase in CRACID, however, could well be an increase in delivery rather than a change in systemic $\mathrm{pH}$ or $\mathrm{Pa}_{\mathrm{CO}_{2}}$. Measurements of $\mathrm{Na}^{+} /$ $\mathrm{H}^{+}$exchange in chronic hypercapnia have shown conflicting results. In the rabbit, $\mathrm{Na}^{+} / \mathrm{H}^{+}$exchange is stimulated by chronic hypercapnia $(14,27-29)$, but in the rat, no effect has been demonstrated $(30,31)$.

Respiratory alkalosis. Acute respiratory alkalosis has been reported to decrease end-proximal bicarbonate reabsorption in the rat $(18,19)$. In these studies, however, $\mathrm{FL}_{\mathrm{HCO}_{3}}$ was lower in the rats with hypocapnia than in the normocapneic controls. This difference could have accounted for a major fraction of the observed reduction in proximal bicarbonate reabsorption. In addition, the degree of hypocapnia was more severe, 18 and $23 \mathrm{mmHg}$, respectively, in the two studies, as compared with $29 \mathrm{mmHg}$ in our study. We found no reduction in either early or overall proximal bicarbonate reabsorption when compared with normocapneic animals with similar $\mathrm{FL}_{\mathrm{HCO}_{3}}$ values (Fig. 2, Tables II and IV). Although the degree of hypocapnia was less than in previous studies, severe alkalemia (arterial $\mathrm{pH}=7.56$ ) was present in our studies. Taken together, these observations suggest that with severe hypocapnia, bicarbonate reabsorption may be blunted in the proximal tubule, but no delivery-independent effect is detectable with moderate acute hypocapnia.

An effect of chronic hypocapnia on bicarbonate reabsorption is evident in our studies at $\mathrm{FL}_{\mathrm{HCO}_{3}}$ values $<800 \mathrm{pmol} / \mathrm{min}$ (Fig. $2 \mathrm{~A}$ and Table II). However, when $\mathrm{FL}_{\mathrm{HCO}_{3}}$ is increased in these animals by plasma expansion, bicarbonate reabsorption is similar to normocapneic animals (Fig. 2, $B$ and $C$ ). Thus, even sustained hypocapnia does not impair the ability of the proximal tubule to increase bicarbonate reabsorption in response to an increase in delivery. Sustained hypocapnia has been shown to decrease $\mathrm{Na}^{+} / \mathrm{H}^{+}$exchange activity in renal cortical brush border membrane vesicles in one study (32) while in another the $V_{\max }$ for $\mathrm{Na}^{+} / \mathrm{H}^{+}$exchange was unaltered but the $V_{\max }$ for $\mathrm{Na}-\mathrm{HCO}_{3}$ cotransport in the basolateral membrane was decreased (29). Whether these changes in activity are a reflection of low delivery or hypocapnia per se is unknown. As in this study, chronic hypocapnia was induced by exposure of animals to hypoxemia in these earlier studies. In our studies, the micropuncture measurements were carried out with $\mathrm{Pa}_{\mathrm{O}_{2}}$ restored to normal values, so that hypoxemia was not a factor at the time of micropuncture. Moreover, when $\mathrm{Pa}_{\mathrm{CO}_{2}}$ has been controlled in previous studies, no specific effect of hypoxemia on renal proton transport has been demonstrated $(32,33)$.

Overview. In intact animal studies, respiratory acidosis and alkalosis have clear and significant effects on renal acid excretion (33-36). Respiratory acidosis induces a transient increase in net acid excretion $(33,35,36)$, and respiratory alkalosis transiently suppresses net acid excretion (34). In the chronic steady state in both disorders, however, net acid excretion returns to control levels, and acid balance is maintained at a new bicarbonate concentration $(34,36)$. The present findings are consistent with these previous studies and, taken together with other studies, suggest the following sequence of events during induction and maintenance of these disorders. Induction of respiratory acidosis stimulates collecting duct $\mathrm{H}^{+}$secretion (37-39), an effect that can account for the increase in net acid excretion that occurs. Addition to the circulating plasma of the new bicarbonate generated by this change in acid excretion increases bicarbonate concentration and, assuming no fall in GFR, increases $\mathrm{FL}_{\mathrm{HCO}_{3}}$. The increase in $\mathrm{FL}_{\mathrm{HCO}_{3}}$ leads to an increase in proximal tubular bicarbonate reabsorption, and also in distal bicarbonate delivery. Augmentation of proximal bicarbonate reabsorption contributes to the maintenance of a high bicarbonate concentration, as does the increase in distal reabsorption of this anion that must occur. The change in distal bicarbonate delivery and reabsorption could also serve to consume a larger fraction of the hydrogen ions secreted in this portion of the nephron, an effect that would dampen net acid excretion and return it to control levels. Exposure to respiratory alkalosis induces an opposite sequence of events. Net acid excretion falls (presumably due to a decrease in distal nephron $\mathrm{H}^{+}$secretion), leading to acid retention and a fall in plasma bicarbonate concentration (34). As a result, $\mathrm{FL}_{\mathrm{HCO}_{3}}$ falls and proximal reabsorption falls in parallel. The reduction in $\mathrm{FL}_{\mathrm{HCO}_{3}}$ decreases distal bicarbonate delivery, a change that could act to restore net acid excretion to normal levels, despite a reduction in overall distal $\mathrm{H}^{+}$secretion. In sustained respiratory alkalosis, in addition, the alkaline $\mathrm{pH}$ independently influences proximal bicarbonate reabsorption (Fig. $2 A$ ).

The sequence of events proposed above for adaptation to respiratory acidosis and alkalosis, of course, remains speculative. Other factors may well contribute to the complex renal response to these acid-base disorders. Nonetheless, delivery-induced changes in proximal bicarbonate reabsorption appear to play a very prominent role in this response. The manner in which changes in $\mathrm{FL}_{\mathrm{HCO}_{3}}$ signal the proximal tubule to change its bicarbonate reabsorptive pattern remains to be determined. Whatever the mechanism, the response is rapid, being manifest within $1 \mathrm{~h}$ of changing $\mathrm{FL}_{\mathrm{HCO}_{3}}$ in micropuncture studies $(2,4)$, and occurring within minutes in in vivo microperfusion studies $(9,10)$. Further studies are required to delineate the nature of this response. 


\section{References}

1. Liu, F.-Y., and M. G. Cogan. 1984. Axial heterogeneity in the rat proximal convoluted tubule. I. Bicarbonate, chloride, and water transport. Am. J. Physiol. 247 (Renal Fluid Electrolyte Physiol. 16):F816-F821.

2. Liu, F.-Y., and M. G. Cogan. 1986. Axial heterogeneity of bicarbonate, chloride, and water transport in the rat proximal convoluted tubule. Effects of change in luminal flow rate and of alkalemia. J. Clin. Invest. 78:1547-1557.

3. Maddox, D. A., L. J. Atherton, W. M. Deen, and F. J. Gennari. 1984. Proximal $\mathrm{HCO}_{3}^{-}$reabsorption and the determinants of tubular and capillary $\mathrm{PCO}_{2}$ in the rat. Am. J. Physiol. 247 (Renal Fluid Electrolyte Physiol. 16):F73-F81.

4. Maddox, D. A., and F. J. Gennari. 1985. Load dependence of $\mathrm{HCO}_{3}$ and $\mathrm{H}_{2} \mathrm{O}$ reabsorption in the early proximal tubule of the Munich-Wistar rat. Am. J. Physiol. 248 (Renal Fluid Electrolyte Physiol. 17):F113-F121.

5. Maddox, D. A., and F. J. Gennari. 1986. Load dependence of proximal tubular bicarbonate reabsorption in chronic metabolic alkalosis in the rat. J. Clin. Invest. 77:709-716.

6. Maddox, D. A., J. F. Horn, F. C. Famiano, and F. J. Gennari. 1986. Load dependence of proximal tubular fluid and bicarbonate reabsorption in the remnant kidney of the Munich-Wistar rat. J. Clin. Invest. 77:1639-1649.

7. Maddox, D. A., and F. J. Gennari. 1987. The early proximal tubule: a high-capacity delivery-responsive reabsorptive site. Am. J. Physiol. 252 (Renal Fluid Electrolyte Physiol. 21):F573-F584.

8. Maddox, D. A., W. M. Deen, and F. J. Gennari. 1987. Control of bicarbonate and fluid reabsorption in the proximal convoluted tubule. Semin. Nephrol. 7:72-81.

9. Liu, F.-Y., and M. G. Cogan. 1987. Kinetics of bicarbonate transport in the early proximal convoluted tubule. Am. J. Physiol. 253 (Renal Fluid Electrolyte Physiol. 22):F912-F916.

10. Liu, F.-Y., and M. G. Cogan. 1988. Flow dependence of bicarbonate transport in the early $\left(\mathrm{S}_{1}\right)$ proximal convoluted tubule. Am. J. Physiol. 254 (Renal Fluid Electrolyte Physiol. 23):F851-F855.

11. Jacobson, $\mathrm{H}, \mathrm{R}, 1981$. Effects of $\mathrm{CO}_{2}$ and acetazolamide on bicarbonate and fluid transport in rabbit proximal tubules. Am. J. Physiol. 240 (Renal Fluid Electrolyte Physiol. 9):F54-F62.

12. Schwartz, G. J., and Q. Al-Awqati. 1985. Carbon dioxide causes exocytosis of vesicles containing $\mathrm{H}^{+}$pumps in isolated perfused proximal and collecting tubules. J. Clin. Invest. 75:1638-1644.

13. Kunau, R. T., Jr., J. I. Hart, and K. A. Walker. 1985. Effect of metabolic acidosis on proximal tubular total $\mathrm{CO}_{2}$ absorption. Am. J. Physiol. 249 (Renal Fluid Electrolyte Physiol. 18):F62-F68.

14. Krapf, R. 1989. Mechanisms of adaptation to chronic respiratory acidosis in the rabbit proximal tubule. J. Clin. Invest. 83:890-896.

15. Sasaki, S, C. A. Berry, and F. C. Rector, Jr. 1982. Effect of luminal and peritubular $\mathrm{HCO}_{3}^{-}$concentrations and $\mathrm{PCO}_{2}$ on $\mathrm{HCO}_{3}^{-}$reabsorption in rabbit proximal convoluted tubules perfused in vitro. J. Clin. Invest. 70:639-649.

16. De Mello Aires, M., and G. Malnic. 1975. Peritubular pH and $\mathrm{PCO}_{2}$ in renal tubular acidification. Am. J. Physiol. 228:1766-1774.

17. Santella, R. N., F. J. Gennari, and D. A. Maddox. 1989. Metabolic acidosis stimulates bicarbonate reabsorption in the early proximal tubule. Am. J. Physiol. 257 (Renal Fluid Electrolyte Physiol. 26):F35-F42.

18. Cogan, M. G. 1984. Effects of acute alterations in $\mathrm{PCO}_{2}$ on proximal $\mathrm{HCO}_{3}^{-}, \mathrm{Cl}^{-}$, and $\mathrm{H}_{2} \mathrm{O}$ reabsorption. Am. J. Physiol. 246 (Renal Fluid Electrolyte Physiol. 15):F21-F26.

19. Malnic, G., M. de Mello Aires, and G. Giebisch. 1972. Micropuncture study of renal tubular hydrogen ion transport in the rat. Am. J. Physiol. 222:147158.
20. Levine, D. Z. 1971. Effect of acute hypercapnia on proximal tubular water and bicarbonate reabsorption. Am. J. Physiol. 221:1164-1170.

21. Maddox, D. A., and F. J. Gennari. 1983. Proximal tubular bicarbonate reabsorption and $\mathrm{PCO}_{2}$ in chronic metabolic alkalosis in the rat. J. Clin. Invest. 72:1385-1395.

22. Maddox, D. A., D. C. Price, and F. C. Rector, Jr. 1977. Effects of surgery on plasma volume and salt and water excretion in rats. Am. J. Physiol. 233 (Renal Fluid Electrolyte Physiol. 2):F600-F606.

23. Vurek, G. G., D. G. Warnock, and R. Corsey. 1975. Measurement of picomole amounts of carbon dioxide by calorimetry. Anal. Chem. 47:765-767.

24. Motulsky, H. J., and L. A. Ransnas. 1987. Fitting curves to data using nonlinear regression: a practical and nonmathematical review. FASEB (Fed. Am. Soc. Exp. Biol.) J. 1:365-374.

25. Cogan, M. G. 1984. Chronic hypercapnia stimulates proximal bicarbonate reabsorption in the rat. J. Clin. Invest. 74:1942-1947.

26. Warren, Y., R. G. Luke, M. Kashgarian, and H. Levitin. 1970. Micropuncture studies of chloride and bicarbonate absorption in the proximal renal tubule of the rat in respiratory acidosis and in chloride depletion. Clin. Sci. (Lond.). 38:375-383.

27. Talor, Z., Y. Wu-Chang, J. Shuffield, E. Sack, and J. A. L. Arruda. 1987. Chronic hypercapnia enhances $V_{\max }$ of $\mathrm{Na}-\mathrm{H}$ antiporter of renal brush-border membranes. Am. J. Physiol. 253 (Renal Fluid Electrolyte Physiol. 22):F394F400.

28. Yang, W., J. A. L. Arruda, and Z. Talor. 1987. $\mathrm{Na}^{+}-\mathrm{H}^{+}$antiporter in posthypercapnic state. Am. J. Physiol. 253 (Renal Fluid Electrolyte Physiol. 22):F833-F840.

29. Ruiz, O. S., J. A. L. Arruda, and Z. Talor. 1989. $\mathrm{Na}_{-} \mathrm{HCO}_{3}$ cotransport and $\mathrm{Na}-\mathrm{H}$ antiporter in chronic respiratory acidosis and alkalosis. Am. J. Physiol. 256 (Renal Fluid Electrolyte Physiol. 25):F414-F420.

30. Northrup, T. E., S. Garella, E. Perticucci, and J. J. Cohen. 1988. Acidemia alone does not stimulate rat renal $\mathrm{Na}^{+}-\mathrm{H}^{+}$antiporter activity. Am. J. Physiol. 255 (Renal Fluid Electrolyte Physiol. 24):F237-F243.

31. Zeidel, M. L., and J. L. Seifter. 1988. Regulation of $\mathrm{Na} / \mathrm{H}$ exchange in renal microvillus vesicles in chronic hypercapnia. Kidney Int. 34:60-66.

32. Hilden, S. A., C. A. Johns, and N. E. Madias. 1989. Adaptation of rabbit renal cortical $\mathrm{Na}^{+}-\mathrm{H}^{+}$exchange activity in chronic hypocapnia. Am. J. Physiol. 257 (Renal Fluid Electrolyte Physiol. 26):F615-F622.

33. Sapir, D. G., D. Z. Levine, and W. B. Schwartz. 1967. The effects of chronic hypoxemia on electrolyte and acid-base equilibrium: an examination of normocapneic hypoxemia and of the influence of hypoxemia on the adaptation to chronic hypercapnia. J. Clin. Invest. 46:369-377.

34. Gennari, F. J., M. B. Goldstein, and W. B. Schwartz. 1972. The nature of the renal adaptation to chronic hypocapnia. J. Clin. Invest. 51:1722-1730.

35. Polak, A., G. G. Haynie, R. M. Hayes, and W. B. Schwartz. 1961. Effects of chronic hypercapnia on electrolyte and acid-base equilibrium. I. Adaptation. $J$. Clin. Invest. 40:1223-1237.

36. Schwartz, W. B., N. C. Brackett, and J. J. Cohen. 1965. The response of extracellular hydrogen ion concentration to graded degrees of chronic hypercapnia: the physiologic limits of the defense of pH. J. Clin. Invest. 44:291-301.

37. Bengele, H. H., M. L. Graber, and E. A. Alexander. 1983. Effect of respiratory acidosis on acidification by the medullary collecting duct. Am. J. Physiol. 244 (Renal Fluid Electrolyte Physiol. 13):F89-F94.

38. Bengele, H. H., J. H. Schwartz, E. R. McNamara, and E. A. Alexander. 1986. Effect of buffer infusion during acute respiratory acidosis. Am. J. Physiol. 250 (Renal Fluid Electrolyte Physiol. 19):F115-F119.

39. Verlander, J. W. K. M. Madsen, and C. C. Tisher. 1987. Effect of acute respiratory acidosis on two populations of intercalated cells in rat cortical collecting duct. Am. J. Physiol. 253 (Renal Fluid Electrolyte Physiol. 22):F1142-F1156. 